Thorax (1967), 22, 453.

\title{
Regional and overall inequality of ventilation and blood flow in patients with chronic airflow obstruction ${ }^{1}$
}

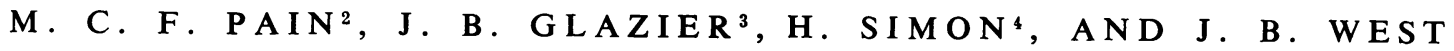 \\ From the Clinical Respiratory Physiology Research Group, Royal Postgraduate Medical School of \\ London, W.12
}

\begin{abstract}
Measurements of the topographical distribution of pulmonary blood flow and ventilation have been made in 26 subjects with chronic irreversible obstructive lung disease using a radioactive xenon scanning technique. The distribution of blood flow was found to range between a normal gradient and the reverse of normal. Differences between left and right lungs were present in patients with associated bronchiectasis, previous lobectomy, and obvious radiological emphysema but not in most of those subjects with no obvious destructive changes. Ventilation was commonly decreased towards the base of the lung, that is the reverse of the normal pattern. Acetylcholine altered the blood flow distribution pattern in three out of nine subjects and this may represent vasodilatation in hypoxic regions of the lung. Repeatability of the scanning technique was found to be $10 \%$ (one standard deviation) for blood flow measurements and $11 \%$ for single-breath ventilation measurements. Examination of the expired xenon plateaux following a single inhalation of xenon in air consistently revealed a fall in count rate with expired volume, indicating the presence of poorly ventilated alveoli. However, there was a poor correlation between the degree of ventilatory inequality revealed by external counting on the one hand and the slope of the expired plateau on the other. The shape of the expired xenon plateau following xenon injection was usually horizontal and correlated poorly with the topographical distribution of blood flow. This is evidence that the extent of the inequality of ventilation-perfusion ratios at the alveolar level in patients with chronic lung disease cannot be obtained by external counters.
\end{abstract}

With the introduction of radioactive gas techniques (Dyson, Hugh-Jones, Newbery, Sinclair, and West, 1960 ; Ball, Stewart, Newsham, and Bates, 1962), it has become possible to measure the topographical distribution of blood flow and ventilation in the lungs of normal subjects and patients with various cardiac and pulmonary diseases. In the normal lung, the unevenness of ventilation and blood flow observed by external counting apparently accounts for most of the inequality of ventilation-perfusion ratios which impairs overall gas exchange (West, 1962). Thus the alveolar-arterial difference for oxygen which can be calculated from the observed distributions

1Supported by the Medical Research Council

"Work done during tenure of an N.S.W. Joint Coal Board Travel Grant. Present address: Respiratory Unit, Royal Melbourne Hospital, Melbourne, Australia

${ }^{3}$ Post-dootoral Research Fellow of the National Heart Institute, U.S.A.

"Supported by the Deutscher Akademischer Austauschdienst and by the British Council of ventilation and blood flow agrees reasonably well with that measured by sampling arterial blood. However, ventilation-perfusion ratio inequality is far more serious in diseased lungs, and it is therefore important to determine how far these new radioactive gas techniques reveal the differences in blood flow and ventilation which are responsible for the defective gas exchange and, ultimately, for respiratory failure.

In this paper we describe a new technique for assessing inequality of blood flow in the lung by recording the concentration of radioactive xenon in expired gas after an injection of a saline solution of the gas. Together with measurements of the expired concentration following a single inhalation of the radioactive gas, this technique gives a measure of the overall inequality of blood flow and ventilation in the lung.

A correlation between these measurements and the observed topographical differences in blood 
flow and ventilation has been sought in a series of patients with chronic airflow obstruction. In some patients, measurements were made before and after the infusion of acetylcholine to see whether this drug affected the pattern of ventilationperfusion ratio inequality.

\section{MATERIALS AND METHODS}

The 26 patients were drawn from a hospital population. Most were outpatients studied after a routine visit, but several were inpatients recovering from an acute exacerbation of their illness. Spirometry by standard techniques had revealed a reduction in the ratio of forced expiratory volume to vital capacity (F.E.V.1.0/V.C. \%) to below $70 \%$ with no significant improvement following a bronchodilator, which consisted of two inhalations of isoprenaline sulphate B.P., $20 \mathrm{mg}$. $/ \mathrm{ml}$. Some further clinical data are set out in Table I.

The topographical distributions of pulmonary blood flow and ventilation were measured using ${ }^{133} \mathrm{Xe}$ and external scanning, as previously described (Dollery and Gillam, 1963). In addition, the subjects were connected via a mouthpiece and polythene tube (I.D. $1.7 \mathrm{~cm}$., dead space $15 \mathrm{ml}$.) which passed through a collimated scintillation counter to a three-way tap and spirometer (Fig. 1). In this way expired or inspired xenon activity and volume could be monitored. Complete exhalation following breath-holding after intravenous injection or inhalation of ${ }^{133} \mathrm{Xe}$ gave a record

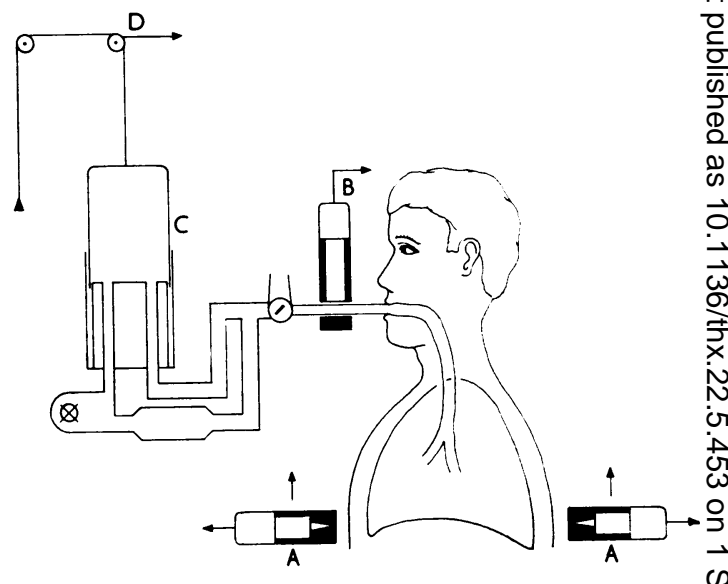

FIG. 1. Diagrammatic representation of external scanning( and expired scintillation counters and spirometer. $(A) T w \sigma_{\overparen{D}}$ pairs of vertical scanning counters (one pair over each 3 lung); (B) counter for expired breath activity; $(C)$ lcad shielded closed-circuit spirometer; $(D)$ potentiometer for volume signal.

of 'alveolar' xenon radioactivity and volume. The ratemeter time constant of the scanning circuits was 0.2 sec. and the time constant for the mouth counter was $0 \cdot 1$ second. The scanning speed was $4 \mathrm{~cm}$./ second. Electrical signals of spirometer volume, expired breath radioactivity, radioactivity measured by right and left

T A B L E I

CLINICAL DATA

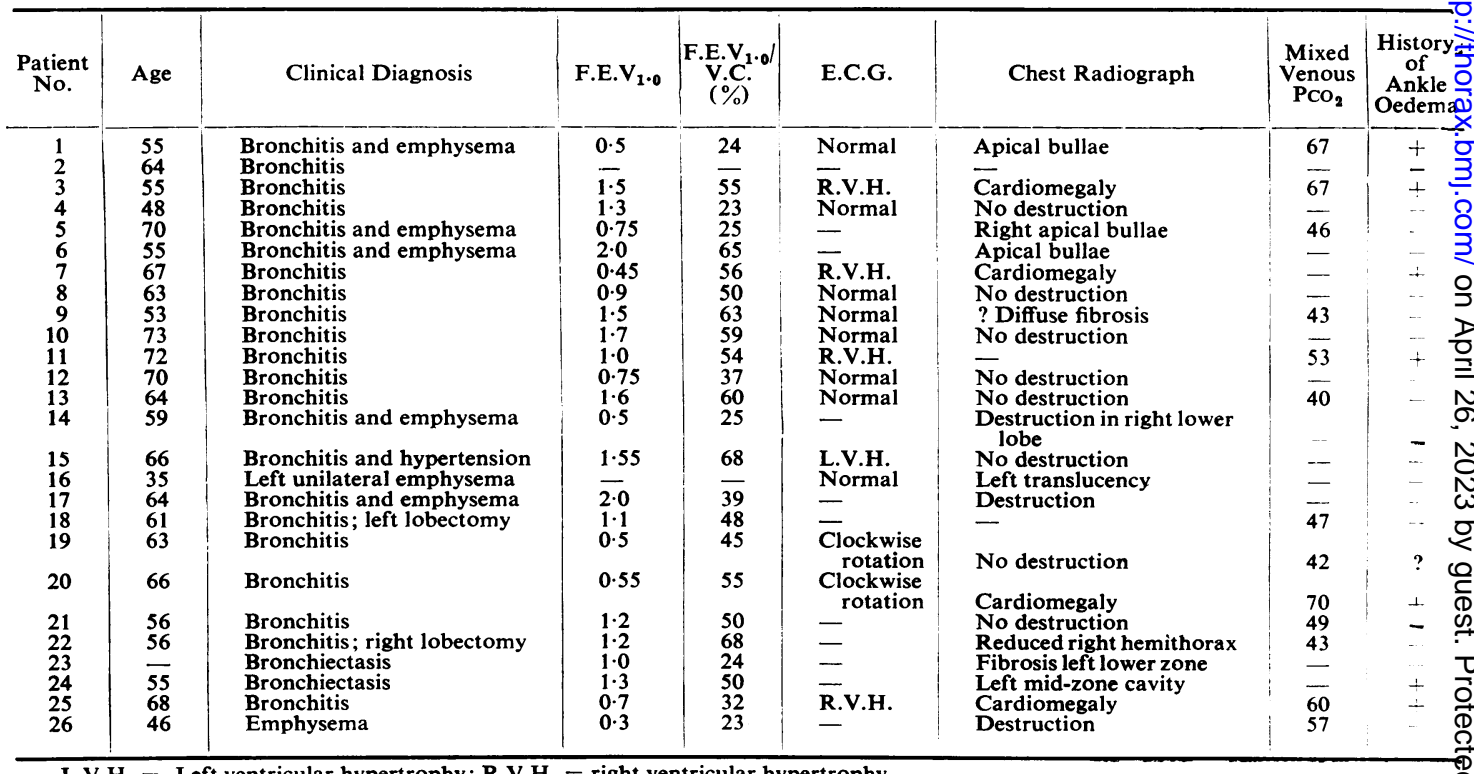

L.V.H. = Left ventricular hypertrophy; R.V.H. $=$ right ventricular hypertrophy 
pairs of scanning counters, and scanner height marker were all displayed on an ultraviolet recorder (S.E.L. 2000).

In nine subjects $(6,9,12,13,15,16,23,24$, and 26) the initial two measurements of the distribution of pulmonary blood flow were followed by two further measurements 3 and 6 minutes after beginning an infusion of acetylcholine. The acetylcholine was delivered at a rate of 8 to $12 \mathrm{mg}$. $/ \mathrm{min}$. into the polythene catheter used for the xenon injection which lay in the superior vena cava. After the end of the infusion, and again after a delay of 10 minutes, two single breath measurements of ventilation distribution were performed and the rebreathing procedure was carried out.

To obtain data about the repeatability of the radioactive measurements, two separate control injections, using identical radioactivities, and two inhalations were performed. The same rebreathing scan was used for calculating the perfusion and ventilation per unit volume for both the control measurements and for the measurements made during acetylcholine infusion.

\section{CAlCUlation OF RESUlts}

Scanning At each 2-cm. interval up the lung scan, the ordinate of the injection scan was divided by the ordinate of the rebreathing scan to give the ratio of pulmonary blood flow per unit alveolar volume, and similarly the ordinates of the single inhalation scan and rebreathing scan allowed the ventilation per unit volume to be obtained. For the purposes of comparison between patients and between individual lungs, the pulmonary blood flow and ventilation ratios for the region $2 \mathrm{~cm}$. either side of the second rib (three measurements) were averaged to give an upper zone ratio, and the lower three ratios overlying lung tissue (measured from chest radiographs) were averaged to give a lower zone ratio. The three ratios situated midway between the upper and lower regions were averaged to give a middle zone ratio. All ratios were then scaled so that the middle zone ratio of the left lung was unity. The factor used to produce this was then applied to the right lung ratios. In this way differences between lungs were preserved.

Expired plateaux If a subject takes a single breath of an inert gas, for example xenon, and then exhales, the slope of the plot of expired concentration against volume is a measure of uneven ventilation (Comroe and Fowler, 1951). This is because poorly ventilated areas of the lung empty last, and these contain relatively small amounts of the tracer gas. In the same way, the slope of the expired alveolar concentration against volume following an injection of radioactive xenon dissolved in saline will be a measure of uneven perfusion. This is because the xenon concentration in any area of the lung will depend on its blood flow per unit volume. It is clear, however, that perfusion inequality will only be revealed in so far as areas of the lung having different blood flows empty at different times during expiration.

The expired activity (expressed as a percentage of the maximum count rate) was calculated at the volumes when $750 \mathrm{ml}$. and $1,250 \mathrm{ml}$. had been exhaled. The results for a particular plateau were expressed as the percentage change in xenon count rate per $500 \mathrm{ml}$. of expirate. In a few patients the total expired volume was less than $1,250 \mathrm{ml}$. and in these the calculations were performed over the last $500 \mathrm{ml}$. The time lag between the record of the count rate of expired xenon and the volume record was less than 0.25 second.

\section{RESULTS}

Table II sets out the results of xenon scanning for each lung for blood flow and ventilation distribution in all patients. Two patients were unable to complete the test and ventilation data were not obtained.

PULMONARY BLOOD FLOW It was possible to divide the patients into four categories:

A, those with essentially different blood flow patterns between left and right lungs (subjects 17 to 26 ) ;

B, those with similar patterns in each lung with a gradient of decreasing perfusion with increasing vertical height (subjects 1 to 9);

$\mathrm{C}$, those with an approximately uniform pattern of blood flow throughout both lungs (subjects 10 to 15$)$; and

$D$, subject 16 , with an inverted pattern of pulmonary blood flow.

Of the 10 patients in group $A$, two had undergone previous lobectomy on the topographically abnormal side, two had lower lobe bronchiectasis, and two had radiological evidence of emphysema on the abnormal side. Hence, six of the 10 subjects had a reason for the anatomic discrepancy in blood flow patterns. The four others in this group could well have had emphysema or bronchiectasis. None of them was given acetylcholine and any part that functional mechanisms played in producing the difference in blood flow patterns remains unknown.

PULMONARY VENTILATION A similar grouping was possible in considering the distribution of a single inspirate : 
T A B L E I I

DISTRIBUTIONS OF PULMONARY BLOOD FLOW AND VENTILATION FOUND WITH RADIOACTIVE XENON

\begin{tabular}{|c|c|c|c|c|c|c|c|c|c|c|c|c|c|c|}
\hline \multirow{3}{*}{$\begin{array}{c}\text { Patient } \\
\text { No. }\end{array}$} & \multicolumn{6}{|c|}{ Blood Flow/Volume } & \multicolumn{6}{|c|}{ Ventilation/Volume } & \multirow{3}{*}{$\begin{array}{c}\text { Blood } \\
\text { Flow } \\
\text { Pattern }\end{array}$} & \multirow{3}{*}{$\begin{array}{l}\text { Ventila- } \\
\text { tion } \\
\text { Pattern }\end{array}$} \\
\hline & \multicolumn{3}{|c|}{ Left Lung } & \multicolumn{3}{|c|}{ Right Lung } & \multicolumn{3}{|c|}{ Left Lung } & \multicolumn{3}{|c|}{ Right Lung } & & \\
\hline & $\mathbf{U Z}$ & MZ & $\mathbf{L Z}$ & $\mathbf{U Z}$ & $\mathbf{M Z}$ & $\mathbf{L Z}$ & UZ & $\mathbf{M Z}$ & $\mathbf{L Z}$ & $\mathbf{U Z}$ & $\mathbf{M Z}$ & $\mathbf{L Z}$ & & \\
\hline $\begin{array}{r}1 \\
2 \\
3 \\
4 \\
5 \\
6 \\
7 \\
8 \\
9 \\
10 \\
11 \\
12 \\
13 \\
14 \\
15 \\
16 \\
17 \\
18 \\
19 \\
20 \\
21 \\
22 \\
23 \\
24 \\
25 \\
26\end{array}$ & $\begin{array}{l}0.61 \\
0.42 \\
0.47 \\
0.56 \\
0.83 \\
1.0 \\
1.0 \\
1.0 \\
0.71 \\
0.89 \\
0.8 \\
0.92 \\
0.6 \\
1.0 \\
1.2 \\
1.5 \\
0.45 \\
0.55 \\
0.33 \\
1.2 \\
0.8 \\
0.8 \\
1.4 \\
1.0 \\
0.37 \\
0.63\end{array}$ & $\begin{array}{l}1.0 \\
1.0 \\
1.0 \\
1.0 \\
1.0 \\
1.0 \\
1.0 \\
1.0 \\
1.0 \\
1.0 \\
1.0 \\
1.0 \\
1.0 \\
1.0 \\
1.0 \\
1.0 \\
1.0 \\
1.0 \\
1.0 \\
1.0 \\
1.0 \\
1.0 \\
1.0 \\
1.0 \\
1.0 \\
1.0\end{array}$ & $\begin{array}{l}1.85 \\
1.5 \\
1.2 \\
1.3 \\
1.7 \\
2.0 \\
1.3 \\
1.2 \\
0.9 \\
1.1 \\
1.1 \\
0.83 \\
0.8 \\
0.71 \\
1.0 \\
0.6 \\
0.7 \\
1.1 \\
2.3 \\
1.35 \\
1.3 \\
1.2 \\
2.0 \\
1.5 \\
1.6 \\
1.5\end{array}$ & $\begin{array}{l}0.61 \\
0.42 \\
0.38 \\
0.44 \\
0.75 \\
0.8 \\
1.6 \\
0.84 \\
0.65 \\
0.89 \\
0.89 \\
0.8 \\
1.2 \\
0.63 \\
1.1 \\
2.6 \\
0.55 \\
0.9 \\
0.33 \\
1.65 \\
0.93 \\
0.55 \\
2.9 \\
0.93 \\
0.87 \\
0.7\end{array}$ & $\begin{array}{l}1.5 \\
0.92 \\
0.85 \\
0.93 \\
0.91 \\
1.2 \\
1.8 \\
0.84 \\
1.0 \\
1.1 \\
0.95 \\
0.92 \\
1.2 \\
0.63 \\
0.92 \\
2.0 \\
1.0 \\
1.5 \\
0.33 \\
2.1 \\
0.93 \\
0.66 \\
3.5 \\
1.1 \\
0.68 \\
1.0\end{array}$ & $\begin{array}{l}2.3 \\
1.1 \\
1.4 \\
1.0 \\
1.3 \\
1.5 \\
2.2 \\
1.2 \\
1.2 \\
1.2 \\
0.95 \\
1.1 \\
1.0 \\
0.73 \\
0.92 \\
1.5 \\
1.4 \\
1.1 \\
0.2 \\
1.3 \\
1.0 \\
0.44 \\
3.5 \\
0.93 \\
0.81 \\
1.0\end{array}$ & $\begin{array}{l}1.6 \\
1.0 \\
1.8 \\
1.2 \\
1.2 \\
1.0 \\
1.5 \\
1.0 \\
1.0 \\
1.2 \\
1.3 \\
1.0 \\
1.0 \\
1.0 \\
1.3 \\
1.1 \\
1.3 \\
0.92 \\
1.0 \\
0.82 \\
0.88 \\
0.93 \\
1.4 \\
0.63\end{array}$ & $\begin{array}{l}1.0 \\
1.0 \\
1.0 \\
1.0 \\
1.0 \\
1.0 \\
1.0 \\
1.0 \\
1.0 \\
1.0 \\
1.0 \\
1.0 \\
1.0 \\
1.0 \\
1.0 \\
1.0 \\
1.0 \\
1.0 \\
1.0 \\
1.0 \\
1.0 \\
1.0 \\
1.0 \\
1.0\end{array}$ & $\begin{array}{l}1.0 \\
1.0 \\
0.35 \\
0.41 \\
1.0 \\
2.0 \\
0.5 \\
1.0 \\
0.65 \\
0.77 \\
0.66 \\
1.0 \\
1.0 \\
0.4 \\
0.83 \\
0.87 \\
0.75 \\
1.1 \\
1.4 \\
0.82 \\
1.1 \\
1.0 \\
0.76 \\
1.0\end{array}$ & $\begin{array}{l}1.2 \\
1.0 \\
1.8 \\
1.3 \\
1.2 \\
0.83 \\
7.0 \\
1.4 \\
0.86 \\
1.2 \\
1.6 \\
1.0 \\
1.0 \\
0.7 \\
0.9 \\
0.93 \\
1.0 \\
0.92 \\
2.0 \\
0.68 \\
0.88 \\
1.3 \\
1.3 \\
0.43\end{array}$ & $\begin{array}{l}0.66 \\
1.0 \\
1.0 \\
0.83 \\
1.2 \\
1.0 \\
4.0 \\
1.0 \\
1.0 \\
0.92 \\
1.3 \\
1.0 \\
1.0 \\
0.6 \\
0.83 \\
0.87 \\
1.5 \\
0.92 \\
2.0 \\
0.82 \\
1.2 \\
1.1 \\
1.3 \\
1.0\end{array}$ & $\begin{array}{l}0.4 \\
1.0 \\
0.35 \\
0.83 \\
1.0 \\
1.8 \\
2.5 \\
1.0 \\
0.57 \\
0.46 \\
0.66 \\
1.0 \\
1.0 \\
0.6 \\
1.5 \\
0.93 \\
\\
1.3 \\
0.85 \\
1.0 \\
0.55 \\
1.4 \\
0.46 \\
0.82 \\
1.2\end{array}$ & $\begin{array}{l}\text { B } \\
\text { B } \\
\text { B } \\
\text { B } \\
\text { B } \\
\text { B } \\
\text { B } \\
\text { B } \\
\text { B } \\
\text { C } \\
\text { C } \\
\text { C } \\
\text { C } \\
\text { C } \\
\text { C } \\
\text { D } \\
\text { A } \\
\text { A } \\
\text { A } \\
\text { A } \\
\text { A } \\
\text { A } \\
\text { A } \\
\text { A } \\
\text { A } \\
\text { A }\end{array}$ & $\begin{array}{l}\text { D } \\
\text { C } \\
\text { D } \\
\text { D } \\
\text { C } \\
\text { B } \\
\text { D } \\
\text { C } \\
\text { D } \\
\text { D } \\
\text { D } \\
\text { C } \\
\text { C } \\
\text { A } \\
\text { A } \\
\text { C }\end{array}$ \\
\hline
\end{tabular}

UZ, MZ, and LZ refer to upper, middle, and lower zone ratios respectively. For explanation of patterns, see text.

Group A (subjects 14, 18, 20, 24, and 15) had a widely different pattern between lungs;

Group B (subjects 6, 23, and 26) had a normal gradient of decreasing ventilation down both lungs ;

Group C (subjects 2, 5, 8, 12, 13, 16, 19, and 22) had uniform ventilation in both lungs ;

Group D (subjects $1,3,4,7,9$ to 11 , and 25) had an inverted distribution of ventilation in both lungs.

EXPIRED XENON PLATEAUX The percentage changes in count rate per $500 \mathrm{ml}$. for the expirate following xenon injection and inhalation are set out in Table III. The plateaux in 20 subjects were judged satisfactory for analysis; in others, the breath was not held properly during the scanning period.

The shape of the plateau following injection varied from one of rising concentration (shown in Table III as positive values) with increasing expired volume (subjects $8,12,13,19,23$, and 25) to unchanging (less than 10\%) (subjects $1,6,9,10$, $11,14,15,16,20,22$, and 24) to decreasing concentration (subjects 2, 18, and 26). The patterns mean that the poorly ventilated alveoli which emptied last were relatively well perfused in the first group of subjects but poorly perfused in the last group.
SLOPES OF ALVEOLAR PLATEAUX AFTER INJECTION OR INHALATION OF XENON-133

\begin{tabular}{|c|c|c|c|c|c|c|}
\hline \multirow[t]{2}{*}{$\begin{array}{l}\text { Patient } \\
\text { No. }\end{array}$} & \multicolumn{3}{|c|}{$\begin{array}{c}\% \text { Change in Xenon } \\
\text { Radioactivity in Expired } \\
\text { Gas per } 500 \text { ml. following } \\
\text { Injection }\end{array}$} & \multicolumn{3}{|c|}{$\begin{array}{l}\% \text { Change in Xenon } \\
\text { Radioactivity in Expired } \\
\text { Gas per } 500 \mathrm{ml} \text {. after } \\
\text { Inhalation }\end{array}$} \\
\hline & First & Second & Mean & First & Second & Mean \\
\hline $\begin{array}{r}1 \\
2 \\
6 \\
8 \\
9 \\
10 \\
11 \\
12 \\
13 \\
14 \\
15 \\
16 \\
18 \\
19 \\
20 \\
22 \\
23 \\
24 \\
25 \\
26\end{array}$ & $\begin{array}{r}-2 \\
-5 \\
-11 \\
+6 \\
+0 \\
-4 \\
+12 \\
+7 \\
+6 \\
+6 \\
-20 \\
+30 \\
+2 \\
+11 \\
+8 \\
+14 \\
+18\end{array}$ & $\begin{array}{r}-3 \\
-20 \\
-5 \\
-\quad 0 \\
+7 \\
-15 \\
+11 \\
+6 \\
+6 \\
+2 \\
+8 \\
-25 \\
+15 \\
+0 \\
+2 \\
+13 \\
0 \\
+14 \\
-7\end{array}$ & $\begin{array}{r}-3 \\
-13 \\
-5 \\
+11 \\
+3 \\
+4 \\
+4 \\
+14 \\
+11 \\
+7 \\
+4 \\
+4 \\
-23 \\
+23 \\
+1 \\
+7 \\
+11 \\
00 \\
+14 \\
-13\end{array}$ & $\begin{array}{r}-9 \\
-22 \\
-8 \\
-9 \\
-10 \\
-10 \\
-9 \\
-13 \\
-8 \\
-21 \\
-4 \\
-7 \\
-6 \\
-4 \\
-10 \\
-45 \\
-10 \\
-7 \\
-6 \\
-10\end{array}$ & $\begin{array}{l}-15 \\
= \\
-5 \\
-2 \\
-2 \\
-10 \\
-10 \\
-7 \\
-12 \\
-0 \\
-14 \\
-5 \\
-7 \\
-7\end{array}$ & $\begin{array}{r}-9 \\
-19 \\
-8 \\
-9 \\
-8 \\
-10 \\
-5 \\
-13 \\
-8 \\
-16 \\
-7 \\
-9 \\
-9 \\
-7 \\
-10 \\
-5 \\
-12 \\
-6 \\
-6 \\
--9\end{array}$ \\
\hline
\end{tabular}

Positive values indicate rising plateaux. Duplicate measurements
in most cases.

The post-inhalation expired plateau declined $\stackrel{\circ}{\stackrel{D}{D}}$ with increasing expired volume in all subjects. $\stackrel{\odot}{+}$ The fall varied from $25 \%$ to $19 \%$ per $500 \mathrm{ml}$. 꿍 expirate.

ACETYLCHOLINE INFUSION The topographical dis- $\mathbb{\mathbb { D }}$ tributions of blood flow in nine subjects who 
T A B L E I V

EFFECTS OF INFUSING ACETYLCHOLINE (ACh) ON THE DISTRIBUTION OF BLOOD FLOW AND THE SHAPE OF THE ALVEOLAR PLATEAU AFTER XENON INJECTION

\begin{tabular}{|c|c|c|c|c|c|c|c|c|c|}
\hline \multirow{2}{*}{$\begin{array}{c}\text { Patient } \\
\text { No. }\end{array}$} & & \multicolumn{3}{|c|}{ Left Lung } & \multicolumn{3}{|c|}{ Right Lung } & \multirow{2}{*}{$\begin{array}{c}\text { Expired Vol. } \\
\text { (ml.) }\end{array}$} & \multirow{2}{*}{$\begin{array}{c}\% \text { Change } \\
\text { in Xenon } \\
\text { Radio- } \\
\text { activity/ } \\
500 \text { ml. }\end{array}$} \\
\hline & & $\mathbf{U Z}$ & $\mathbf{M Z}$ & $\mathbf{L Z}$ & $\mathbf{U Z}$ & $\mathbf{M Z}$ & $\mathbf{L Z}$ & & \\
\hline 6 & $\begin{array}{l}\text { Control } \\
\text { ACh }\end{array}$ & $\begin{array}{l}1.0 \\
0.93\end{array}$ & $\begin{array}{l}1.0 \\
1.0\end{array}$ & $\begin{array}{l}2 \cdot 0 \\
2 \cdot 0\end{array}$ & $\begin{array}{l}0.8 \\
0.9\end{array}$ & $\begin{array}{l}1 \cdot 2 \\
1 \cdot 2\end{array}$ & $\begin{array}{l}1.5 \\
1.7\end{array}$ & $\begin{array}{l}2,500 \\
3,000\end{array}$ & $\begin{array}{l}-5 \\
-4\end{array}$ \\
\hline 9 & $\begin{array}{l}\text { Control } \\
\text { ACh }\end{array}$ & $\begin{array}{l}0.71 \\
0.74\end{array}$ & $\begin{array}{l}1.0 \\
1.0\end{array}$ & $\begin{array}{l}0.9 \\
0.83\end{array}$ & $\begin{array}{l}0.65 \\
0.79\end{array}$ & $\begin{array}{l}1.0 \\
1 \cdot 0\end{array}$ & $\begin{array}{l}1.2 \\
0.83\end{array}$ & $\begin{array}{l}2,500 \\
2,500\end{array}$ & $\begin{array}{l}+3 \\
+12\end{array}$ \\
\hline 12 & $\begin{array}{l}\text { Control } \\
\mathrm{ACh}\end{array}$ & $\begin{array}{l}0.92 \\
1.0\end{array}$ & $\begin{array}{l}1.0 \\
1.0\end{array}$ & $\begin{array}{l}0.83 \\
0.85\end{array}$ & $\begin{array}{l}0.8 \\
0.8\end{array}$ & $\begin{array}{l}0.92 \\
0.92\end{array}$ & $\begin{array}{l}1 \cdot 1 \\
1 \cdot 0\end{array}$ & $\begin{array}{l}1,500 \\
2,000\end{array}$ & $\begin{array}{l}+13 \\
+8\end{array}$ \\
\hline 13 & $\begin{array}{l}\text { Control } \\
\text { ACh }\end{array}$ & $\begin{array}{l}0.6 \\
0.6\end{array}$ & $\begin{array}{l}1 \cdot 0 \\
1 \cdot 0\end{array}$ & $\begin{array}{l}0.8 \\
1.0\end{array}$ & $\begin{array}{l}1 \cdot 2 \\
08\end{array}$ & $\begin{array}{l}1 \cdot 2 \\
1 \cdot 2\end{array}$ & $\begin{array}{l}1.0 \\
1.4\end{array}$ & $\begin{array}{l}2,500 \\
2,500\end{array}$ & $\begin{array}{l}+11 \\
+11\end{array}$ \\
\hline 15 & $\begin{array}{l}\text { Control } \\
\text { ACh }\end{array}$ & $\begin{array}{l}1 \cdot 2 \\
1 \cdot 2\end{array}$ & $\begin{array}{l}1.0 \\
1.0\end{array}$ & $\begin{array}{l}1 \cdot 0 \\
1 \cdot 2\end{array}$ & $\begin{array}{l}1 \cdot 1 \\
0.8\end{array}$ & $\begin{array}{l}0.92 \\
0.9\end{array}$ & $\begin{array}{l}0.92 \\
1.2\end{array}$ & $\begin{array}{l}2,250 \\
2,250\end{array}$ & $+\begin{array}{r}4 \\
0\end{array}$ \\
\hline 16 & $\begin{array}{l}\text { Control } \\
\text { ACh }\end{array}$ & $\begin{array}{l}1 \cdot 5 \\
1 \cdot 3\end{array}$ & $\begin{array}{l}1.0 \\
1.0\end{array}$ & $\begin{array}{l}0.6 \\
0.87\end{array}$ & $\begin{array}{l}2 \cdot 6 \\
2 \cdot 3\end{array}$ & $\begin{array}{l}2.0 \\
1.9\end{array}$ & $\begin{array}{l}1.5 \\
1.5\end{array}$ & $\begin{array}{l}1,750 \\
1,750\end{array}$ & $\begin{array}{l}+4 \\
+17\end{array}$ \\
\hline 23 & $\begin{array}{l}\text { Control } \\
\text { ACh }\end{array}$ & $\begin{array}{l}1 \cdot 35 \\
1 \cdot 3\end{array}$ & $\begin{array}{l}1.0 \\
1.0\end{array}$ & $\begin{array}{l}2 \cdot 0 \\
2 \cdot 1\end{array}$ & $\begin{array}{l}2 \cdot 9 \\
2.9\end{array}$ & $\begin{array}{l}3 \cdot 5 \\
3 \cdot 5\end{array}$ & $\begin{array}{l}3 \cdot 5 \\
3 \cdot 5\end{array}$ & $\begin{array}{l}1,750 \\
1,750\end{array}$ & $\begin{array}{l}+10 \\
+8\end{array}$ \\
\hline 24 & $\begin{array}{l}\text { Control } \\
\text { ACh }\end{array}$ & $\begin{array}{l}1.0 \\
1.0\end{array}$ & $\begin{array}{l}1.0 \\
1.0\end{array}$ & $\begin{array}{l}1.5 \\
1.6\end{array}$ & $\begin{array}{l}0.93 \\
0.93\end{array}$ & $\begin{array}{l}1 \cdot 1 \\
1 \cdot 1\end{array}$ & $\begin{array}{l}0.93 \\
0.94\end{array}$ & $\begin{array}{l}1,750 \\
1,750\end{array}$ & $\begin{array}{l}\mathbf{0} \\
\mathbf{0}\end{array}$ \\
\hline 26 & $\begin{array}{l}\text { Control } \\
\mathrm{ACh}\end{array}$ & $\begin{array}{l}0.63 \\
0.5\end{array}$ & $\begin{array}{l}1.0 \\
1.0\end{array}$ & $\begin{array}{l}1 \cdot 5 \\
1 \cdot 3\end{array}$ & $\begin{array}{l}0.7 \\
0.55\end{array}$ & $\begin{array}{l}1.0 \\
10\end{array}$ & $\begin{array}{l}1.0 \\
1 \cdot 1\end{array}$ & $\begin{array}{l}1,250 \\
1,250\end{array}$ & $\begin{array}{l}-12 \\
-9\end{array}$ \\
\hline
\end{tabular}

received acetylcholine are shown in Table IV. Four patients showed changes in the pattern of blood flow after acetylcholine which were outside the limits of one standard deviation of a single observation. In three of these there was an increase in perfusion to the lower portion of the lungs with an accompanying decrease of perfusion to the upper portions of one or both lungs (patients 13, 15, and 16). In one patient (no. 9) there was a decrease of lower region perfusion with a small increase to the upper regions.

Only two patients (9 and 16) showed an appreciable change in the shape of the expired plateau after the infusion of acetylcholine. In both instances, the plateau sloped upwards and the slope decreased.

REPEATABILITY OF SCANNING PROCEDURES To measure this, the ratio of blood flow to alveolar volume or ventilation to alveolar volume at the $10-\mathrm{cm}$. and $20-\mathrm{cm}$. level from the bottom of the lung for the first injection or inhalation of xenon was compared with the ratio obtained at the same levels for the second injection or inhalation. Repeatability was $10 \%$ (standard deviation of a single observation) for the blood flow scan (112 measurements) and $11 \%$ for the ventilation scan (72 measurements). The relationships between the duplicate injection and duplicate inhalation procedures are shown in Figures 2 and 3.

\section{DISCUSSION}

Like others who have studied similar types of patients with radioactive xenon (Bentivoglio, Beerel, Stewart, Bryan, Ball, and Bates, 1963 ; Hugh-Jones, Ritchie, and Dollery, 1966), we found considerable differences among our patients in the distribution of both ventilation and blood flow within the lungs.

Before considering these patterns in detail, the possible errors and limitations of the technique will be discussed. The scanning technique requires the subject to breath-hold for about 6 to 7 seconds whilst xenon is being evolved into the alveolar gas volume following injection. Respiratory movement during the time of evolution or during scanning will redistribute the gas and render the scan invalid. In practice, all but a few patients can hold their breath and only technically satisfactory studies have been included in this paper. We were able to assess the adequacy of breath-holding by coupling the spirometer and expired counter through to the patient at the beginning of breath-holding and so even small respiratory movements were readily detected. The errors introduced by using a scanning procedure compared with fixed counters have been discussed previously (Dollery and Gillam, 1963). The repeatability of about $10 \%$ for two measurements includes any differences in patient co-operation as 


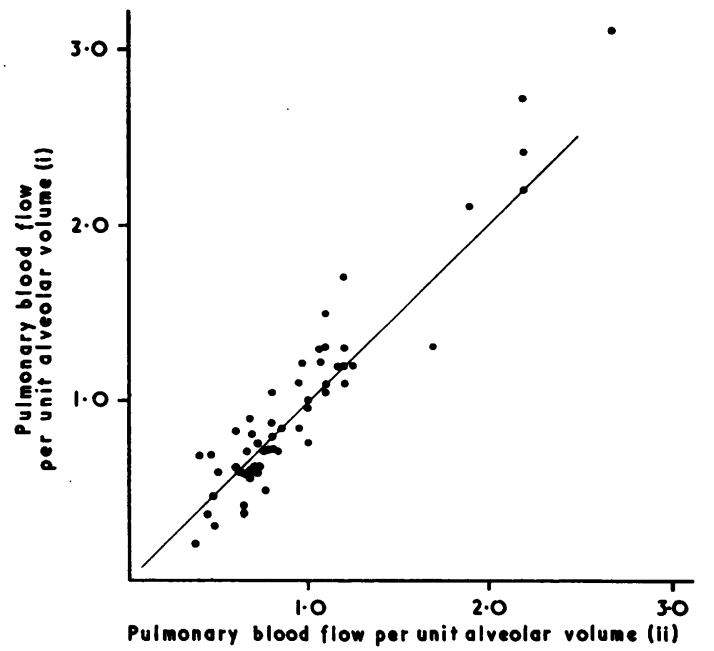

FIG. 2. Ccmparison of first and second determinations of blood flow/unit lung volume as measured 10 and $20 \mathrm{~cm}$. from bottom of lung.

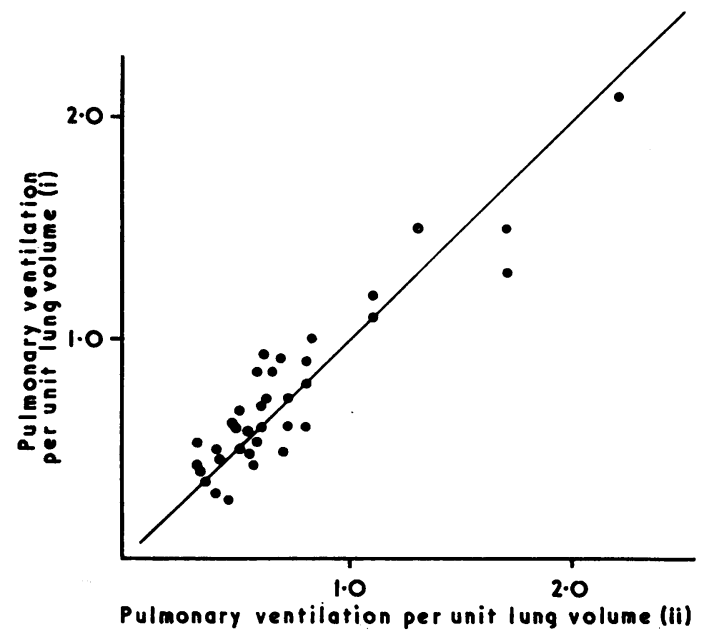

FIG. 3. Comparison of first and second determinations of ventilation/unit lung volume as measured 10 and $20 \mathrm{~cm}$. from bottom of lung.

well as actual changes in blood flow or ventilation distribution over a 15-minute period.

Errors apart from those due to lack of patient co-operation or scanning mainly depend on the presence of poorly ventilated regions of lung. These may be very slow to equilibrate during the rebreathing period so that the volume of a large, poorly ventilated region can be underestimated.
This failure to equilibrate will lead to an overestimate of the blood flow and ventilation per unit volume in the poorly ventilated regions. In a few patients we made scans after rebreathing them for 2 minutes and 5 minutes and compared these. There was no detectable difference in the alveolar volume scans, and this presumably means that the portions of lung were so poorly ventilated that little improvement occurred over this period. The scintillation counter monitoring the expired breath also gave an indication of the extent of equilibrium, and in practice we rebreathed the subject until respiratory fluctuations in the expired-inspired xenon activity had disappeared or for 3 minutes-whichever was the shorter time. However, again it is likely that very poorly ventilated regions contribute so little to expired gas that their influence can remain undetected. The technique does not detect regions which are unventilated and unperfused but contain gas or unventilated, collapsed but perfused regions. With these limitations in mind, the results of the topographical blood flow and ventilation patterns will be considered.

PULMONARY BLOOD FLOW PER UNIT ALVEOLAR VOLUME The nine subjects with an approximately normal perfusion gradient in the presence of gross chronic airflow obstruction are of interest. Such a gradient might be produced by destructive changes in lung tissue, reducing blood flow selectively in the upper regions, or it might indicate no reactive disturbance of the pulmonary circulation to gross disease of the airways without destruction (Read, 1959). Only subjects 1 to 3 approach a normal upper-lower zone ratio of about 1:3 (Glazier and DeNardo, 1966). The remainder, although showing a smooth decrease in perfusion with increasing vertical height, were more uniform with upper-lower zone ratios of about 1:2. Any increase in pulmonary arterial pressure as a result of generalized vasoconstriction would be expected to cause a decrease in perfusion gradient.

The six patients with a uniform blood flow pattern throughout both lungs could have this pattern as a result of loss of functioning tissue predominantly in the lower regions, or as the result of a generalized vasoconstriction producing an increase in blood flow through the upper regions or a local, potentially reversible, reduction in blood flow to a poorly ventilated region. Of the six subjects, patients 12,13 , and 15 were studied following acetylcholine infusion. Subjects 13 and 15 showed a significant $(P<0.05$ and $P<0.01$ respectively) change in the internal distribution of 
blood flow and acutely increased relative perfusion of the most affected lower region.

The single subject with an inverted blood flow pattern, that is severe reduction of perfusion in the lower portions of the lungs (subject 16), also had decreased ventilation to that region. Following acetylcholine, the gradient of perfusion changed towards a more normal uniform pattern $(0.05<\mathrm{P}<0.1)$.

These three patients, subjects 13,15 , and 16, also had reduced ventilation to the lower portions of the lungs. The reduced ventilation is presumably associated with reduced alveolar oxygen tensions in this region. One possible explanation for the disturbances of the blood flow pattern and their reversible nature would be a deviation of pulmonary blood flow away from hypoxic regions as a result of arteriolar constriction. The existence of a mechanism by which regional hypoxia tends to preserve normal ventilation-perfusion relationships has been postulated before in various cardiac and pulmonary conditions (Fishman, 1961).

PULMONARY VENTILATION PER UNIT ALVEOLAR VOLUME As was perhaps expected, a normal pattern of ventilation distribution was unusual and was found in only three subjects. Over the whole series, the commonest pattern was one of inversion of ventilation so that the bulk of a single inspiration was distributed to the upper regions. The reason why the defective ventilation was most common in the lower regions is not clear, though, since these portions of lung are normally the best ventilated, it may suggest that the inequality of ventilation in these patients results from lung damage by inhaled substances. Any tendency for airways to collapse or close would be exaggerated in the lower lobes because of the lower transpulmonary pressure at the base of the vertical lung (Krueger, Bain, and Patterson, 1961 ; MilicEmili, Henderson, Dolovich, Trop, and Kaneko, 1966).

Consideration of all patients with poorly ventilated lower portions of lung showed that there was no clear correlation between the relative perfusion and ventilation of the poorly ventilated region. Patients 1 and 3 , for example, showed a gross mismatch of ventilation and perfusion, most of the blood flow going to the lower regions in spite of an inverted distribution of pulmonary ventilation.

There was no correlation between the extent of airways obstruction as assessed by the F.E.V. . $1 \cdot 0$ and the degree of abnormality of ventilation distribution.
EXPIRED XENON PLATEAUX In patients with uneven ventilation the final portion of the expired plateau is dominated by gas coming from poorly ventilated regions. As a result, the plateau slopes downwards following an inhalation of xenon. However, there was no correlation between the relative ventilation of the worst ventilated region, as shown by scanning the lung, and the slope of the expired plateau (Fig. 4).

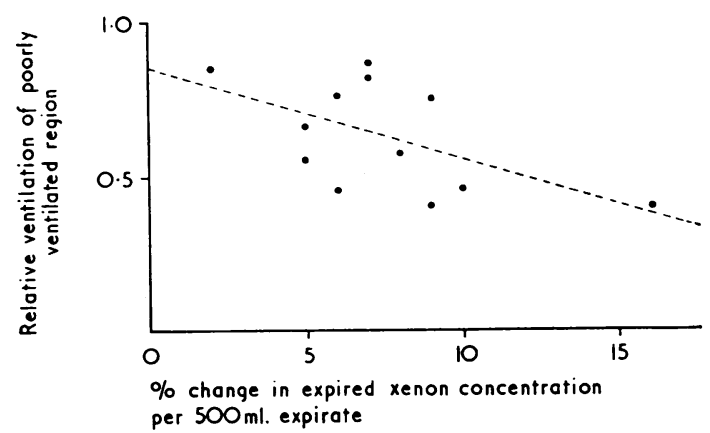

FIG. 4. Relative ventilation of poorly ventilated region as measured with external counters plotted against the inequality of ventilation as measured from expired gas. The correlation is very poor.

Following the injection of xenon, the change in expired xenon concentration plotted against expired volume indicates the relative perfusion of the poorly ventilated alveoli which empty last. Poorly ventilated alveoli with poor perfusion would be expected to produce a declining plateau, but if they are well perfused the plateau should rise. Situations in which alveolar blood flow and alveolar volume are matched throughout the lung or in which there is no uneven ventilation would be expected to result in a flat alveolar plateau.

Figure 5 shows a plot of the relative perfusion of the poorly ventilated region, as determined by the scanning counters, against the change in expired xenon concentration following xenon injection. It is apparent that there is no correlation. Poorly ventilated regions with approximately the same relative perfusion were associated with horizontal and declining plateaux and, conversely, poorly ventilated regions which were well perfused were associated with horizontal or rising plateaux. Patient 2 is an example of the lack of agreement between the patterns of topographical distribution and the plateaux of expired xenon. Topographically, the poorly ventilated lower region was well perfused and yet the expired xenon plateau declined, suggesting that poorly ventilated alveoli were poorly perfused. 


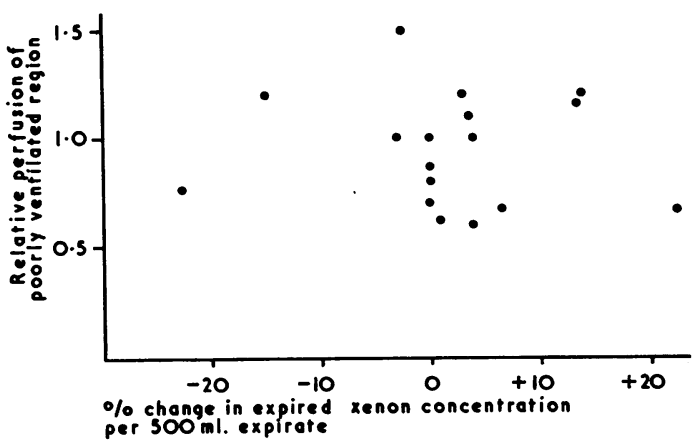

FIG. 5. Relative perfusion of foorly ventilated region as measured with external counters plotted against the inequality of perfusion as measured from expired gas. The correlution is very poor.

Acetylcholine infusion did not produce any striking change in shape of the expired plateaux following xenon injection except in two cases. In subject 16, the plateau became a rising one, suggesting an increase in perfusion to poorly ventilated regions, and this agrees with the apparent topographical change in distribution. Subject 6 , on the other hand, showed a change in plateau from a rising to a horizontal one, suggesting a decrease in perfusion of poorly ventilated alveoli. However, there was no corresponding change in the topographical blood flow pattern.

The commonest plateau following xenon injection was one which sloped less than $5 \%$ (11 out of 20 plateaux). In the undoubted presence of regional ventilatory inequality, a horizontal plateau would suggest that pulmonary alveolar perfusion in these patients is matched to alveolar volume rather than to alveolar ventilation.

The shape of the xenon plateau probably depends on the same factors which can alter the shape of the single-breath nitrogen plateau. Although inhalations were made from functional residual capacity, we made no careful attempt to control inspired volume or expired flow rate. Both of these can produce small changes of importance when the plateau shape is carefully analysed (Young, Martin, and Pace, 1963 ; Nesarajah, 1965). It is unlikely that these factors can cause the large alterations in direction of change of plateau shape which would make it compatible with the topographical distribution and inhomogeneity. For each patient, two expired plateaux were assessed following injection and inhalation of xenon and, although there were sometimes minor differences, in no case was there a radical change in plateau shape between duplicate measurements (Table IV).

One of the striking features of this study was $\stackrel{\overparen{Q}}{\Omega}$ the inability to predict the expired xenon plateau shape from the topographical distribution pattern. One explanation may be that much of the inequality of ventilation and blood flow exists along $\overrightarrow{\vec{\omega}}$ the airways (stratified inhomogeneity). Recently, o the assumption that gaseous diffusion occurs $\overrightarrow{\vec{x}}$ almost instantaneously within alveolar ducts and i alveoli (Rauwerda, 1946) has been questioned $N$ (Cumming, Crank, Horsfield, and Parker, 1966), and these authors contend that a major factor in $\omega$ the shape of the expired plateau is diffusion $ᄋ$ limitations within the abnormal airways. How- ever, any diffusion gradient along the airways $\infty$ after an injection of xenon would cause a rising $\frac{\mathbb{D}}{0}$ plateau of xenon concentration, and since in three $\frac{\mathbb{\Phi}}{3}$ patients the plateau fell faster than $10 \%$ per 500 요 ml., this seems good evidence that in these patients at least other factors were responsible for the $\vec{\varnothing}$ shape of the alveolar plateau.

Topographical scanning using xenon-133 can measure the relative blood flow and ventilation going to the particular region the counters are looking at (that is, a core of lung tissue 8 to $10 \%$ $\mathrm{cm}$. in diameter), but it does not give information $\stackrel{\mathbb{D}}{\stackrel{2}{2}}$ about the alveolar ventilation and capillary blood $\overrightarrow{\vec{P}}$ flow relationships within this large region. It is $\frac{9}{3}$ these relationships at the alveolar level which are the major determinant of effective gas exchange. Topographical studies of the diseased lung with radioactive xenon should not therefore be used 을 to derive the degree of inequality of ventilation- $\underset{x}{x}$ perfusion ratios as they affect overall gas $\frac{\dot{\sigma}}{2}$ exchange.

The skilled technical assistance of Mr. G. Forse and Mr. G. Kingaby is gratefully acknowledged. 윽 Patients were studied through the kindness of Dr. C. M. Fletcher and Dr. E. J. M. Campbell.

\section{REFERENCES}

Ball, W. C., Stewart, P. B., Newsham, L. G. S., and Bates, D. V.

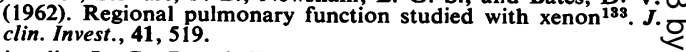

Bentivoglio, L. G., Beerel, F., Stewart, P. B., Bryan, A. C., Ball W. C., and Bates, D. V. (1963). Studies of regional ventilation and perfusion in pulmonary emphysema using xenon ${ }^{133}$. Amer. Rev. resp. Dis., 88, 315.

Comroe, J. H., and Fowler, W. S. (1951). Detection of uneven alveolar ventilation during a single breath of oxygen. Amer. J. Med., 10, 408.

Cumming, G., Crank, J., Horsfield, K., and Parker, I. (1966). Gaseous $\overparen{D}$ diffusion in the airways of the human lung. Resp. Physiol., 1, 58.

Dollery, C. T., and Gillam, P. M. S. (1963). The distribution of blood $\mathbb{D}$ and gas within the lungs measured by scanning after administration of ${ }^{183} \mathrm{Xe}$. Thorax, 18, 316 . 
Dyson, N. A., Hugh-Jones, P., Newbery, G. R., Sinclair, J. D., and West, J. B. (1960). Studies of regional lung function using radioactive oxygen. Brit. med. J., 1, 231.

Glazier, J. B., and De Nardo, G. L. (1966). Pulmonary function studied with the Xenon ${ }^{133}$ scanning technique. Normal values and a postural study. Amer. rev. Resp. Dis., 94, 188.

Hugh-Jones, P., Ritchie, B. C., and Dollery, C. T. (1966). Surgical treatment of emphysema. Brit. med. J., 1, 1133.

Krueger, J. J., Bain, T., and Patterson, J. L. (1961). Elevation gradien of intrathoracic pressure. J. appl. Physiol., 16, 465.

Milic-Emili, J., Henderson, J. A. M., Dolovich, M. B., Trop, D., and Kaneko, K. (1966). Regional distribution of inspired gas in the lung. Ibid., 21, 749.
Nesarajah, M. S. (1965). Factors influencing the measurement of inequalities of ventilation and of ventilation-perfusion ratios in the lung by the single breath test. J. Physiol. (Lond.), 181, 71P.

Rauwerda, P. E. (1946). Unequal ventilation of different parts of the lung and the determination of cardiac output. Thesis, Groningen University.

Read, J. (1959). Pulmonary ventilation and perfusion in normal subjects and in patients with emphysema. Clin. Sci., 18, 465.

West, J. B. (1962). Regional differences in gas exchange in the lung of erect man. J. appl. Physiol., 17, 893.

Young, A. C., Martin, C. J., and Pace, W. R., Jr. (1963). Effect of expiratory flow patterns on lung emptying. Ibid., 18, 47. 